\title{
Effect of proton pump inhibitors on platelet inhibition activity of clopidogrel in Chinese patients with percutaneous coronary intervention
}

This article was published in the following Dove Press journal:

Vascular Health and Risk Management

24 June 2011

Number of times this article has been viewed

Joanne Kwan'

Wah Wah Htun ${ }^{2}$

Yili Huang ${ }^{3}$

Wilson $\mathrm{Ko}^{3}$

Tak W Kwan ${ }^{3}$

'Boston University, Boston, MA, USA; ${ }^{2}$ Lutheran Medical Center, Brooklyn, NY, USA; ${ }^{3}$ Beth Israel Medical Center, New York, NY, USA
Correspondence:TakW Kwan

Asian Services Center, 139 Centre St,

Room 307, New York, NY 10013 , USA

Tel + I 2123343507

Fax + I 2123344728

Email kwancardio@aol.com
Background: The purpose of this study was to examine the effect of proton pump inhibitors (PPI) on the antiplatelet activity of clopidogrel in a consecutive series of Chinese patients after they had received coronary stents.

Methods: A sample of 51 consecutive Chinese patients treated with coronary stents and taking PPI and clopidogrel for more than 30 days were enrolled in this study. Mean values for platelet residual units and percentage inhibition before PPI (+PPI) and 14 days after discontinuation of PPI (-PPI) were compared using the paired $t$-test.

Results: There was no effect of concomitant use of esomeprazole and clopidogrel or omeprazole and clopidogrel on the inhibition assay, but platelet residual units and percentage inhibition showed statistically significant improvement after stopping lansoprazole in Chinese patients who were on chronic clopidogrel therapy. Clopidogrel resistance existed more frequently in the Chinese-American population examined, and was as high as $68 \%$ (+PPI) to $73 \%$ (-PPI).

Conclusion: The clopidogrel resistance found is cause for concern, although its relationship with clinical events is currently unknown in this population. Further study with other thienopyridines or genetic variant analysis is suggested.

Keywords: proton pump inhibitors, clopidogrel resistance, Chinese population, percutaneous coronary intervention

\section{Introduction}

Stent thrombosis remains a serious complication of coronary artery stent implantation. Despite routine dual antiplatelet therapy with acetylsalicylic acid and thienopyridines, the incidence of stent thrombosis persists at a rate of $0.5 \%-2 \% .{ }^{1}$ Several factors have been associated with an increased risk of stent thrombosis, ie, long and multiple stents, stent malapposition, residual dissection, lack of dual antiplatelet drugs, and platelet polymorphism. ${ }^{2,3}$ Resistance to acetylsalicylic acid and clopidogrel has been suggested as a possible cause of stent thrombosis, but conclusive data are lacking. Although low responders to clopidogrel had a significantly higher risk of major cardiovascular events $(22.7 \%$ versus $5.6 \%)$, wide interindividual variability in platelet responsiveness to clopidogrel among individuals remains a topic of intense debate. ${ }^{4,5}$

Proton pump inhibitors (PPI) have been advocated to lower the gastrointestinal bleeding risk in patients receiving the combination of aspirin and clopidogrel ${ }^{6,7}$ However, recent data suggest that PPI may lower the antiplatelet effect of clopidogrel in patients undergoing coronary stent implantation. ${ }^{8}$ Angiolillo et al suggested in their recent study that a metabolic drug-drug interaction exists between clopidogrel and omeprazole but not between clopidogrel and pantoprazole. ${ }^{9}$ This controversial drug interaction could be 
important among Chinese-American patients, who have an increased ulcer bleeding risk and are known to have the most frequent cytochrome P450 (CYP) 2C19 loss-of-function mutation, which is important for clopidogrel metabolism. ${ }^{10}$ In this study, we examined the effect of PPI on the antiplatelet activity of clopidogrel in a consecutive series of Chinese patients after they received coronary stents.

\section{Methods}

Fifty-one consecutive immigrant Chinese patients treated with coronary stenting and PPI were enrolled in this prospective study. Patients were included if they had been on chronic ( $>30$ days) clopidogrel therapy. Patients with active gastrointestinal bleeding or history of massive gastrointestinal bleeding requiring blood transfusion were excluded from the trial. Other exclusion criteria included malignancy, oral coumadin, or platelet count $<100 \times 10^{9} / \mathrm{L}$. After patients gave informed consent, platelet inhibition assays before (+PPI) and 14 days after discontinuation of PPI (-PPI) were obtained using the VerifyNow ${ }^{\circledR}$ P2Y12 (Accumetrics Inc, San Diego, CA) assay. ${ }^{11}$

\section{Platelet function assay}

VerifyNow was approved by the US Food and Drug Administration in 2005. The VerifyNow P2Y12 assay is a whole blood, point-of-care assay, which consists of an instrument and a single-use assay device containing the biochemical reagents required to perform the assay. A venous blood sample was collected in $3.2 \%$ citrate with a loose tourniquet through a short venous catheter inserted into a forearm vein. Platelet function testing 4-6 hours after the last dose of clopidogrel was performed. A multiple syringe technique was used and the first $2 \mathrm{~mL}$ of blood was discarded. Percentage inhibition of platelets and the P2Y12 reactivity unit were measured in order to assess responsiveness to clopidogrel. In addition to $20 \mu \mathrm{m}$ adenosine diphosphate, $22 \mathrm{nM}$ prostaglandin E1 is incorporated into the VerifyNow P2Y12 assay device to suppress intracellular free calcium levels and thereby reduce the contribution from adenosine diphosphate binding to P2Y12 receptors. In a separate channel in which iso-TRAP is used as an agonist, a baseline value for platelet function was obtained. The VerifyNow P2Y12 assay reports patient results as P2Y12 reaction units, inhibition, and the baseline value in less than five minutes. Percentage inhibition was calculated as $(\mathrm{P} 2 \mathrm{Y} 12$ reactivity units/baseline $) \times 100$. The hospital institutional review board approved this research. The study data are presented as means \pm standard deviation, counts, or percentages if not otherwise stated. Mean values of continuous variables were compared using the one-tailed paired $t$-test. $P$ values $<0.05$ were considered statistically significant.

\section{Results}

Fifty-one patients were enrolled into this study. Seven patients dropped out (three continued to take their PPI, one declined the second blood draw, one was not on a PPI at all, one had severe anemia after day 1 , and one had severe gastritis). A total of 96 blood samples and 44 patients were analyzed in this study (Table 1) after excluding the initial seven samples of first blood drawn for patients who dropped out.

There was no statistically significant difference overall between the three different +PPI versus -PPI samplings for percentage inhibition $(19.95 \% \pm 9.78 \%$ versus $20.88 \% \pm 15.70 \%, P=0.30)$ and $\mathrm{P} 2 \mathrm{Y} 12$ reactivity units $(267 \pm 65.4$ versus $275 \pm 70.1, P=0.15$, Figures $1 \mathrm{~A}$ and $1 \mathrm{~B})$. In subgroup analyses of the three different PPI, there were no differences in percentage inhibition or P2Y12 reactivity units for concomitant usage of esomeprazole and clopidogrel and omeprazole and clopidogrel. However, there was a statistically significant improvement in platelet inhibition by clopidogrel 14 days after cessation of lansoprazole $(P=0.013$ for $\mathrm{P} 2 \mathrm{Y} 12$ reactivity units and $P=0.04$ for percentage inhibition, Table 2). Subgroup analyses in terms of diabetes, age, gender, and smoking also did not show any significant differences in percentage inhibition or $\mathrm{P} 2 \mathrm{Y} 12$ reactivity units (Table 3 ). When a $\mathrm{P} 2 \mathrm{Y} 12$ reactivity unit level $\geq 235$ was used for the cutoff according to Price et al, ${ }^{12} 68 \%$ of the +PPI samples and $73 \%$ of -PPI samples were nonresponders. When $<40 \%$ inhibition was considered as a poor response to clopidogrel by Cambo et al, ${ }^{13}$ $84 \%$ of +PPI and $91 \%$ of -PPI patients were nonresponders (Figures $2 \mathrm{~A}$ and $2 \mathrm{~B}$ ).

Table I Patient demographics

\begin{tabular}{ll}
\hline $\mathrm{n}$ & 44 \\
Age (years) & $54-86$ (mean 73) \\
Male & $25(57 \%)$ \\
Smoking & $10(23 \%)$ \\
Diabetes mellitus & $16(37 \%)$ \\
Hypertension & $38(87 \%)$ \\
Hyperlipidemia & $33(75 \%)$ \\
History of MI & $6(14 \%)$ \\
History of CABG & $5(11 \%)$ \\
History of PTCA & $26(59 \%)$ \\
ESRD & $5(11 \%)$ \\
Taking aspirin & $29(67 \%)$ \\
Taking statins & $25(57 \%)$ \\
\hline
\end{tabular}

Abbreviations: MI, myocardial infarction; CABG, coronary artery bypass graft; PTCA, percutaneous transluminal coronary angioplasty; ESRD, end-stage renal disease. 

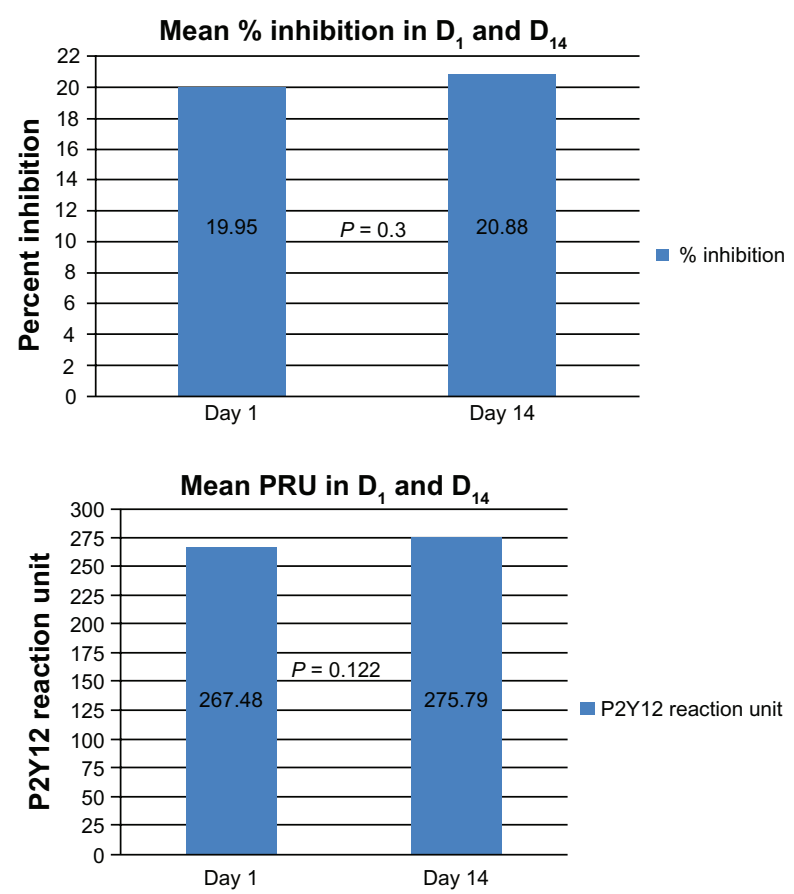

Figure I (A) Mean percent inhibition of clopidogrel between day I and day 14 (B) Mean P2YI2 reaction units between day I and day 14 .

Abbreviation: PRU, $\mathrm{P} 2 \mathrm{Y} I 2$ reaction unit.

\section{Discussion}

Our small, single-center study suggests that there was no effect of concomitant use of esomeprazole and clopidogrel and omeprazole and clopidogrel on the inhibition assay in our Chinese study population. Furthermore, as previously described, P2Y12 reactivity units and percentage inhibition showed a statistically significant improvement after stopping lansoprazole in patients who were on chronic clopidogrel therapy. However, there were only six patients in the lansoprazole group. Interestingly, clopidogrel resistance existed more frequently in the Chinese-American population examined, being as high as $68 \%$ (+PPI) to $73 \%$ (-PPI). This is cause for concern, although the correlation with clinical events is currently unknown in this population.

Clopidogrel is a prodrug, which requires conversion by the liver primarily via CYP3A4 and CYP2C19 to an active metabolite, which irreversibly binds to the platelet adenosine diphosphate receptor. ${ }^{14} \mathrm{CYP} 2 \mathrm{C} 19$ metabolic activity is highly variable among patients because of genetic variation. Several gene variants associated with reduced or absent CYP2C19 activity exist, although the CYP2C19*2 allele accounts for more than $90 \%$ of cases of poor metabolism. ${ }^{15}$ Metabolic activation by CYP2C19 has emerged as a crucial determinant of the pharmacodynamics and clinical efficacy of clopidogrel. Lack of metabolism has contributed to a higher rate of recurrent cardiovascular events compared with noncarriers. ${ }^{16}$

PPI, notably omeprazole and lansoprazole, are strong inhibitors of CYP2C19 activities. Ex vivo biological studies have suggested that coadministration of omeprazole or lansoprazole may decrease the antiplatelet effect of clopidogrel, whereas this interaction was not reported with other PPI, such as pantoprazole or esomeprazole. ${ }^{17}$ Our data also suggest that lansoprazole decreases the antiplatelet effect of clopidogrel, but that omeprazole and clopidogrel do not. Recent studies have questioned the validity of actual interactions between clopidogrel and PPI, whether this interaction is the $\mathrm{pH}$-mediated effect of gastrointestinal absorption as a class effect, or a CYP2C19-mediated effect of metabolism with clopidogrel as the victim and PPI as the perpetrator. ${ }^{18}$ Studies suggested that some PPI may affect the conversion of clopidogrel to its active metabolite by possible inhibition of CYP2C19, but the exact mechanism of this drug-drug interaction remains to be determined. There is also speculation as to whether the use of PPI reduces the clinical efficacy of clopidogrel. Several population-targeted studies have reported that use of PPI increases the risk for cardiac events in clopidogrel-treated patients. ${ }^{19}$ Whether a differential effect exists between individual PPI was unclear. It was noted in several editorials that the lack of risk adjustment was a limitation of several of these early studies..$^{20}$ For this reason, regulatory authorities have indicated the need for further investigations regarding this important health care issue.

In coronary patients who carry the genetic variant associated with a loss of function of the CYP2C19 enzyme, the risk of stent thrombosis on clopidogrel treatment is 3-6-fold higher. ${ }^{21,22}$ However, the influence and magnitude of risk of the CYP2C19 genotype have been inconsistent among studies. ${ }^{23} \mathrm{~A}$ recent genome-wide association study has shown that common variants in the CYP2C19 gene locus are the dominant explanation for variance in the

Table 2 P2YI 2 reaction units and percentage inhibition for different proton pump inhibitors

\begin{tabular}{|c|c|c|c|c|c|c|c|}
\hline PPI & $\mathbf{n}$ & Mean PRU $D_{1} \pm S D$ & Mean PRU $D_{14} \pm$ SD & $P$ value & Mean \% Inh $D_{1} \pm$ SD & Mean $\% \operatorname{lnh} D_{14} \pm S D$ & $P$ value \\
\hline Esomeprazole & 27 & $273.52 \pm 58$ & $270.85 \pm 52$ & 0.35 & $17.18 \pm 13$ & $20.34 \pm 13$ & 0.08 \\
\hline Omeprazole & II & $247.2 \pm 63$ & $260.3 \pm 107$ & 0.26 & $26 \pm 17$ & $27.7 \pm 23$ & 0.39 \\
\hline Lansoprazole & 6 & $273.14 \pm 101$ & $317 \pm 91$ & 0.01 & $22 \pm 20.5$ & $13.14 \pm 15.46$ & 0.04 \\
\hline
\end{tabular}

Abbreviations: PRU, P2Y 12 reaction units; \% Inh, percent inhibition; SD, standard deviation. 
Table 3 Subgroup analyses for $\mathrm{P} 2 \mathrm{Y} / 2$ reaction units and percentage inhibition

\begin{tabular}{|c|c|c|c|c|c|c|c|}
\hline & $\mathbf{n}$ & Mean PRU D, & Mean PRU D 14 & $P$ value & Mean \% Inh $D_{1}$ & Mean \% Inh $D_{14}$ & $P$ value \\
\hline Diabetes + & 17 & 281.23 & 304.94 & 0.18 & 18.47 & 17.17 & 0.4 \\
\hline- & 27 & 258.81 & 257.44 & 0.46 & 20.89 & 23.22 & 0.29 \\
\hline Smoking + & 11 & 264.09 & 276.27 & 0.37 & 24.36 & 23.36 & 0.45 \\
\hline- & 33 & 268.6 & 275.63 & 0.32 & 18.48 & 20.06 & 0.33 \\
\hline Age $\leq 73$ & 24 & 263.1 & 262.5 & 0.48 & 19.25 & 20.6 & 0.38 \\
\hline$>73$ & 20 & 271.12 & 286.87 & 0.25 & 20.54 & 21.12 & 0.45 \\
\hline
\end{tabular}

Abbreviations: PRU, P2Y I 2 reaction unit; \% Inh, percentage inhibition.

antiplatelet response to clopidogrel. ${ }^{24}$ Among the variants of CYP2C19, the $* 2$ and $* 3$ variants are the most common loss-of-function alleles. The presence of the CYP2C19*3 allele is very rare in Caucasians and very common in East Asians, especially in Chinese populations $(7 \%-10 \%){ }^{25-30}$ In a study by Luo et al, the presence of the CYP2C $19 * 2$ (loss-of-function) allele in different populations is as follows: Mexican Americans (9.7\%), Caucasians (12.7\%), AfricanAmericans (18.2\%), and Chinese (29\%). ${ }^{31}$ Wang et al showed clopidogrel resistance in $16.8 \%$ of their post-percutaneous coronary intervention population, with $16.9 \%$ of this group suffering composite thrombotic events versus $6.2 \%$ of the clopidogrel-responsive group. ${ }^{32}$ The consequences of these variants include a significantly increased risk for bleeding, myocardial infarction, stent thrombosis, and death. With
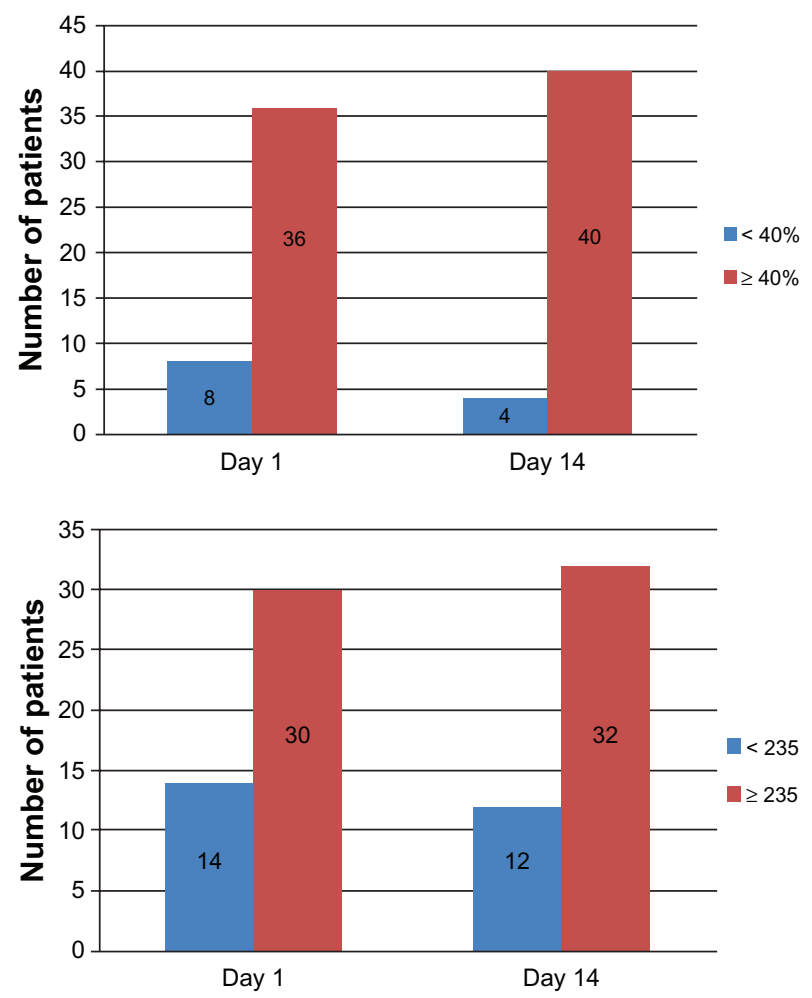

Figure 2 (A) Number of patients responding to clopidogrel using mean percentage inhibition $<40 \%$. (B) Number of patients responding to clopidogrel using mean $\mathrm{P} 2 \mathrm{Y}$ I 2 reaction units $\geq 235$. stent thrombosis rates in carriers of CYP2C19 as high as $11 \%$, mortality associated with such events is close to $50 \%$. There is a nearly two-fold increase in the risk of bleeding in CYP2C19*17 gain-of-function mutation carriers because of increased clopidogrel activation. We should thus take a more vigilant approach in these patients to prevent catastrophic outcomes. ${ }^{33}$ Although patients with diabetes mellitus are reported to be decreased metabolizers of clopidogrel, we did not find any statistically significant difference in P2Y12 reactivity units and percentage inhibition between diabetic and nondiabetic patients. ${ }^{34}$

Individualized dual antiplatelet agents may help overcome some of the shortcomings of hyporesponders. Investigators have recently demonstrated an eight-fold reduction in stent thrombosis by administering additional loading doses of clopidogrel in patients with a poor baseline response. ${ }^{35}$ Analyses limited to data from clopidogrel-treated patients have shown a relative risk of major cardiovascular events that was increased by a factor of 1.53-3.69 among carriers of lossof-function alleles as compared with noncarriers, including a 1.7-2.4-fold increase in risk of subacute stent thrombosis. ${ }^{36}$ On the basis of these findings and related pharmacokinetic and pharmacodynamic data (Clinicaltrials.gov number, NCT01123824), the Food and Drug Administration has issued a black box warning about reduced effectiveness of clopidogrel in patients who are carriers of two loss-of function alleles and has suggested that carriers of these alleles should receive a higher dose of clopidogrel or an alternative antiplatelet agent. In some instances, up to $2400 \mathrm{mg}$ was required to achieve optimal antiplatelet effects. In addition, recent data suggested that doubling of the clopidogrel maintenance dose in the initial implantation period could confer significant benefit. Furthermore, prasugrel, a newly approved thienopyridine with more rapid and greater inhibition of platelets, has now emerged as a viable option. Another possible option in the near future will be ticagrelor, the first of a new class of orally active nonthienopyridine agents, which has a reversible antiplatelet effect and does not require activation. Furthermore, this agent has a faster 
and more consistent antiplatelet effect compared with current standard treatment. ${ }^{22}$

Critics of CYP2C19 suggest that the predictive capacities of these tests are modest compared with genotyping and, notably, do not foretell a patient's risk for bleeding. Other problems with platelet function tests include results that are inconsistent and dynamic when assessed at different time points in the same patient, lack of a standard definition of suboptimal platelet response, and disagreement on the best method for measuring platelet function. Hence, current evidence supports the prototype of individualized medical therapy in the future. Translational medicine has transformed the current practice of medicine to specific personalized algorithms to provide optimal medical therapy. Further study of other thienopyridines or genetic variant analysis is suggested.

The limitations of our study are as follows. First, it was conducted at a single center and had a relatively small sample size, although was larger than some others reported in the literature. Second, the PPI 14-day washout period may not be enough for some patients. Third, clinical outcomes were not assessed. Alternative methods of platelet function testing, such as vasodilatation-stimulated phosphoprotein phosphorylation, should be used to validate this single test result. Nonetheless, this study sheds some light on hyporesponsiveness to clopidogrel in Chinese-American patients on chronic therapy.

\section{Disclosure}

The authors report no conflicts of interest in this work.

\section{References}

1. Schomig A, Neumann FJ, Kastrati A, et al. A randomized comparison of antiplatelet and anticoagulant therapy after the placement of coronaryartery stents. N Engl J Med. 1996;334:1084-1089.

2. Cutlip DE, Baim DS, Ho KK, et al. Stent thrombosis in the modern era: a pooled analysis of multicenter coronary stent clinical trials. Circulation. 2001;103:1967-1971.

3. Kastrai A, Koch W, Berger PB, et al. Prospective role against restenosis from an interleukin-1 receptor antagonist gene polymorphism in patients treated with coronary stenting. $J$ Am Coll Cardiol. 2000;36:2168-2173.

4. Grubel PA, Bliden KP, Hiatt BL, O'Connor CM. Clopidogrel for coronary stenting: response variability, drug resistance, and the effect of pretreatment platelet reactivity. Circulation. 2003;107:2908-2913.

5. Price MJ, Colman JL, Steinhubl SR, Wong GB, Cannon CP, Teirstein PS. Onset and offset of platelet inhibition after high-dose clopidogrel loading and standard daily therapy measured by a point-of-care assay in healthy volunteers. Am J Cardiol. 2006;98:681-684.

6. Lai KC, Lam SK, Chu KM, et al. Lansoprazole for the prevention of recurrences of ulcer complications from long-term low-dose aspirin use. N Engl J Med. 2002;346:2033-2038.

7. Chan FK, Chung SC, Suen BY, et al. Preventing recurrent upper gastrointestinal bleeding in patients with Helicobacter pylori infection who are taking low-dose aspirin or naproxen. $N$ Engl J Med. 2001;344:967-973.

8. Laine L. Approaches to nonsteroidal anti-inflammatory drug use in the high-risk patient. Gastroenterology. 2001;120:594-606.
9. Angiolillo DJ, Gibson CM, Cheng S, et al. Differential effects of omeprazole and pantoprazole on the pharmacodynamics and pharmacokinetics of clopidogrel in healthy subjects: randomized, placebocontrolled, crossover comparison studies. Clin Pharmacol Ther. 2011:89:65-74.

10. Lim TM, Lu PY, Meheshinder S, et al. An audit of upper gastrointestinal bleeding at Seremba Hospital. Med J Malaysia. 2003;58:522-525.

11. Malinin A, Pokov A, Spergling M, et al. Monitoring platelet inhibition after clopidogrel with the VerifyNow-P2Y $12^{\circledR}$ rapid analyzer: the VERIfy Thrombosis risk ASsessment (VERITAS) study. Thromb Res. 2007;1119:227-284.

12. Price MJ, Endemann S, Gollapudi RR, et al. Prognostic significance of post-clopidogrel platelet reactivity assessed by a point-of-care assay on thrombotic events after drug-eluting stent implantation. Eur Heart J. 2008;29:992-1000.

13. Campo G, Fileti L, Valgimigli M, Marchesini J, Scalone A, Ferrari R. Boosting platelet inhibition in poor responder to aspirin and clopidogrel undergoing percutaneous coronary intervention: role of tirofiban. J Blood Med. 2010;1:61-69.

14. Hulot JS, Collet JP, Silvain J, et al. Cardiovascular risk in clopdiogreltreated patients according to cytochrome P450 2C19*2 loss-of-function allele or proton pump inhibitor coadministration. $J$ Am Coll Cardiol. 2010;56:134-150

15. Simon T, Verstuyft C, Mary-Krause M, et al. For the French Registry of Acute ST-Elevation and Non-ST-Elevation Myocardial Infarction (FAST-MI) investigators. Genetic determinants of response to clopidogrel and cardiovascular events. N Engl J Med. 2009;360:363-375.

16. Pare G, Mehta S, Yusuf S. Effects of CYP2C19 genotype on outcomes of clopidogrel treatment. $N$ Engl J Med. 2010;365:1-11.

17. Ho PM, Maddox TM, Wang L, et al. Risk of adverse outcomes associated with concomitant use of clopidogrel and proton pump inhibitors following acute coronary syndrome. JAMA. 2009;30:937-944.

18. Juurlink DN, Gomes T, Ko DT, et al. A population-based study of the drug interaction between proton pump inhibitors and clopidogrel. CMAJ. 2009;180:713-718.

19. Shuldiner AR, O'Connell JR, Gurbel PA, et al. Influence of CYP2C19 polymorphism on antiplatelet effects of clopidogrel and long-term recurrent ischemic event occurrence. JAMA. 2009;302:849-858.

20. Siller-Matula JM, Spiel AO, Lang IM, Kreiner G, Christ G, Jilma B. Effects of pantoprazole and esomeprazole on platelet inhibition by clopidogrel. Am Heart J. 2009;157:148.e1-148.e5.

21. Trenk D, Hochholzer W, Fromm MF, et al. Cytochrome P450 2C19 $681 \mathrm{G}>$ A polymorphism and high on-clopidogrel platelet reactivity associated with adverse 1-year clinical outcome of elective percutaneous coronary intervention with drug-eluting or bare-metal stents. J Am Coll Cardiol. 2008;51:1925-1934.

22. Mahoney EM, Wang K, Arnold SV, et al. Cost-effectiveness of prasugrel versus clopidogrel in patients with acute coronary syndromes and planned percutaneous coronary intervention: results from the trial to assess improvement in therapeutic outcomes by optimizing platelet inhibition with Prasugrel-Thrombolysis in Myocardial Infarction TRITON-TIMI 38. Circulation. 2010;121:71-79.

23. Mehta SR, Tanguay JF, Eikelboom JW, et al. Double-dose versus standard-dose clopidogrel and high-dose versus low-dose aspirin in individuals undergoing percutaneous coronary intervention for acute coronary syndromes (CURRENT-OASIS 7): a randomized factorial trial. Lancet. 2010;376:1233-1243.

24. Simon T, Verstuyft C, Mary-Krause M, et al. Genetic determinants of response to clopidogrel and cardiovascular events. $N$ Engl J Med. 2009;360:363-375.

25. Xie HG. Direct evidence for the higher frequency of CYP2C19 allelic heterozygotes Chinese subjects than in white subjects. Clin Pharmacol Ther. 1997;62:691-692.

26. Goldstein JA, Ishizaki T, Chiba K, et al. Frequencies of the defective CYP2C19 alleles responsible for the mephenytoin poor metabolizer phenotype in various Oriental, Caucasian, Saudi. Pharmacogenetics. 1997;7:59-64. 
27. Lee SY, Lee ST, Kim JW. Contributions of CYP2C9/CYP2C19 genotypes and drug interaction to the phenytoin treatment in the Korean epileptic patients in the clinical setting. $J$ Biochem Mol Biol. 2007;40:448-452.

28. Takakubo F, Kuwano A, Kondo I. Evidence that poor metabolizers of (S)-mephenytoin could be identified by haplotypes of CYP2C19 in Japanese. Pharmacogenetics. 1996;6:265-267.

29. Xiao ZS, Goldstein JA, Xie HG, et al. Differences in the incidence of the CYP2C19 polymorphism affecting the S-mephenytoin phenotype in Chinese Han and Bai populations and identification of a new rare CYP2C19 mutant allele. J Pharmacol Exp Ther. 1997;281:604-609.

30. Giusti B, Gori AM, Marcucci R, et al. Cytochrome P450 2 C19 loss-offunction polymorphism, but not CYP3A4 IVS10 + 12G/A and P2Y12 T744C polymorphisms, is associated with response variability to dual antiplatelet treatment in high-risk vascular patients. Pharmacogenet Genomics. 2007;17:1057-1064.

31. Luo HR, Poland Lin KM, Wan YJ. Genetic polymorphism of cytochrome P450 2C19 in Mexican Americans: a cross-ethnic comparative study. Clin Pharmacol Ther. 2006;80:33-40.
32. Wang ZJ, Zhou YJ, Liu YY, et al. Impact of clopidogrel resistance on thrombotic events after percutaneous coronary intervention with drug-eluting stent. Thromb Res. 2009;124:46-51.

33. Tiroch KA, Sibbing D, Koch W, et al. Protective effect of the CYP2C19*17 polymorphism with increased activation of clopidogrel on cardiovascular events. Am Heart J. 2010;160:506-512.

34. Furuta T, Iwaki T, Umemura K. Influences of different proton pump inhibitors on the anti-platelet function of clopidogrel in relation to CYP2C19 genotypes. Br J Clin Pharmacol. 2010;70:383-392.

35. Sim SC, Risinger C, Dahl ML, et al. A common novel CYP2C19 gene variant causes ultrarapid drug metabolism relevant for the drug response to proton pump inhibitors and antidepressants. Clin Pharmacol Ther. 2006;79:103-113.

36. Harmsze AM, van Werkum JW, ten Berg JM, et al. CYP2C19*2 and CYP2C9*3 alleles are associated with stent thrombosis: a case-control study. Eur Heart J. 2010;31:3046-3053.
Vascular Health and Risk Management

\section{Publish your work in this journal}

Vascular Health and Risk Management is an international, peerreviewed journal of therapeutics and risk management, focusing on concise rapid reporting of clinical studies on the processes involved in the maintenance of vascular health; the monitoring, prevention and treatment of vascular disease and its sequelae; and the involvement of

\section{Dovepress}

metabolic disorders, particularly diabetes. This journal is indexed on PubMed Central and MedLine. The manuscript management system is completely online and includes a very quick and fair peer-review system, which is all easy to use. Visit http://www.dovepress.com/ testimonials.php to read real quotes from published authors. 